\title{
A Mica Echelon Grating
}

This content has been downloaded from IOPscience. Please scroll down to see the full text. 1899 Proc. Phys. Soc. London 17664

(http://iopscience.iop.org/1478-7814/17/1/347)

View the table of contents for this issue, or go to the journal homepage for more

Download details:

IP Address: 130.102.42.98

This content was downloaded on 01/10/2015 at 17:29

Please note that terms and conditions apply. 


\section{A Mica Eshelon Grating. By Prof. R. W. Woon*.}

Havisg experienced some difficulty, when discussing Michelson's remarkable retardation-grating, in making students understand how it is possible for the sodium lines to be separated by a distance fifteen or twenty times as great as the distance between the spectra, it struck me that an echelon, built up of very thin films instead of thick plates, coming midway between the ordinary grating and the echelon as commonly constructed, would be useful in demonstrating the theory.

Such a grating I have made of mica.

By it lines, which with an ordinary grating of the same number of grooves would appear single, can be resolved and still not be farther apart than the spectra. It shows spectra of the same general appearance as in the more powerful instruments, can be set for single and double order, and though useless as a tool for research, is almost as satisfactory for purposes of demonstration as the costly batteries of thick plates.

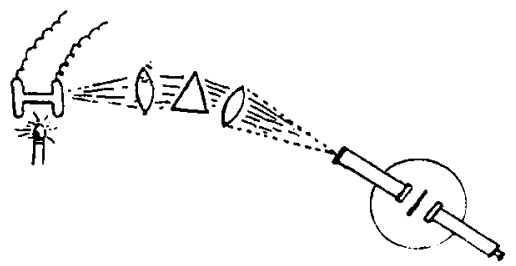

A number of thin sheets of mica were examined with the interferometer, and one selected over a considerable portion of which the fringes appeared straight and unbroken. This area was roughly outlined with a pin-scratch, and fout up, into a dozen small rectangles with a print-trimmer. The retardation of one of these was measured with the interfernmeter, and found to be fifty wave-lengths for sodium-light. The grating would therefore yield spectra of about the 50th order: I say "about," for the order varies with the wave-

* Read February 8, 1901. 
length of the light and the inclination of the grating. A grating-space of $(1.5 \mathrm{~mm}$. was determined upon, and a strip of irlass was accordingly ruled with this spacing on a dividingingine. On this scale the echelon was built up, the plates heing pur in position under the microscope, and cemented at the edges by means of small bits of sealing-wax and a hot wire.

Considerable difficulty was found in attaching each plate without disturbing the spacing of the other. The first two or three yratings that were made were not very satistictory; but some experience having been obtained by practice, an excellent one was finally obtained. Only nine platess were used owing to the opacity of the mica in thicker layers. The hattery was mounted on a square of cardloard over a rectangular opening of the same size, il clear space $0.5 \mathrm{~mm}$. wide heing left to serve as the first grating-line of zero retardation. The whole number of lines was therefore ten.

The resolving-power, represented by the product of the number of lines and the order of the spectrum, would accord. ingly be about 500. Obvionsly the sodiun lines, requiring a product of at least 1000 for resolution, were heyond the power of the instrument; but the two yellow mercury lines, separated by 2.5 times the distance between the $\mathrm{Na}_{\mathrm{a}}$ lines and requiring a product of only 280 , seemed suitable.

The light from an "end-on" mercury-tube, after passing through a collimating-lens and prism, was focussed on the collimator of a spectrometer, the green (monochromatic) image of the tuthe being brought on the slit. On placing the achelon on the table of the instrument the spectra showed clear and sharp, and by turning the grating a little could be hrought into rither single or double position (see Lord Blythswood and Dr. Marchant 's palper, Phil. Mag. Apr. 1900). Faint secondary maxima appeared between the principal maxima, owing to the small number of grating elements.

By slightly shitting the position of the lens, the yellow light from the tule was now focussed on the slit, when the principal maxima immediately donbled in a most beautiful manner and the faint secondary maxima disappeared owing to overlapping. The distance between the components was about one third of the distance between the spectra. For the sake of comparison, a grating of the same spacing and 
number of lines was ruled on a piece of smoked glass. (To prevent the film from tearing it should bo first wetted with alcohol and dried.)

The slit was illuminated with white light, and a cyanine film placed before it. This cut off all but the extreme red and blue; and it was found that in the first order the grating was unable to separate the extreme red and blue of the spectrum, while the echelon easily resolved the $\mathrm{Hg}$ lines, showing the effect of the introduction of retardation.

The constants of the grating were as follows:-

1 the Thickness of plates $0.05 \mathrm{~mm}$.

Width of space $0.5 \mathrm{~mm}$.

Retardation of ench plate, 50 waves.

Calculating the separation of the $\mathrm{Hg}$ lines by Michelson's tormula, we have

$$
\begin{aligned}
\frac{\delta \theta}{\delta \theta_{1}^{-}}=\frac{t}{\lambda} \cdot \frac{\delta \lambda}{\lambda} . \text { where } t & =1 \cdot(15 \mathrm{~mm} . \\
t^{t} & =44, \\
\frac{\delta \lambda}{\lambda} & =280, \\
\delta \theta & =\delta \theta_{1} \frac{94}{280}=\frac{1}{i}:
\end{aligned}
$$

or the distance between the $\mathrm{Hg}$ lines is 1 of the distance hetween the spectra.

It will be found instructive to illuminate the slit-plater of the spectrometer with a focussed continuous spectrum, and observe the way the different orders of echelon spectrin file by when the continuous spectrum is moved across the slit, showing the dependence of order on wave.length.

If the slit be illuminated with white light and a continuous spectrum be formed in the telescope by means of a prism, this spectrum will be found to be crossed by heavy dark bands when the echalon is placed in front of the prism. The explanation of these bands makes a good problem for adranced students. A clew may be found by repeating the experiment with the slit-plate illuminated with the continuous spectrum instend of white light, and moving this spectrum very slowly. 
It may be of interest to som" to know that the Zeemnn effect can be shown with an echelon made of four interferomoter-plates, the light being the green rays firm a merewry tube.

I'hysical Laboratury of the. I'niver'sity of Wisensin. Matdistu.

XLVII. On the Propmintion of Cinsped Waces and their Relation to the Primery and Serondary Focal Lines. B?! Prof. R. W. Woon *.

Ix a previous paper $\dagger$ I have shown the forms of the wavefronts reflected from spherical surfaces, by means of geometrical constructions, and photographs of the actual waves. In the present paper I shall discuss somewhat wore fully the case of the reflexion of a plane wave by a hemispherical mirror, where we have a reflected wave of a form which I have likened to at volcanic cone. A superticial examination if the forms might lead one to imagine that the bowl of the crater collapsed to a point at the principal focus of the mirror. This can of course only be true in the case of a concave spherical wave, which is only given by a parabolic mirror. We sball find as a mitter of fact, if we examine the geometrical construction, that the cusp of the wave, or the rim of the crater, which traces the calustic as I have shown, is continuously passing through a tocus. In other words, the curvature of the crater increases as we go from the bottom to the rim, at which point the radius becomezero. 'The inner alge is then continually passing through : focus and appearing on the outside, building up, us it were, the sides of the cone. These wave-fronts were drawn by constructing the orthogonal surface, which wats shown to $b$. in section an epicycloid formed by rolling a circle whose diameter was equal to the radins of curvature of the mirror, around the outside of the mirror. The evolute of this curve is the caustic, itself an epicycloid, and the reflected wave-front-

- Kead Februnry 22, 1901.

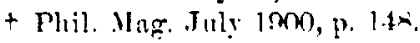

